\begin{tabular}{|c|c|c|c|}
\hline \multirow{3}{*}{$\begin{array}{r}\text { Case Reports in } \\
\text { Gastroenterology }\end{array}$} & \multirow{2}{*}{\multicolumn{2}{|c|}{ Case Rep Gastroenterol 2016;10:146-150 }} & \multirow[b]{3}{*}{$\begin{array}{l}\text { Karger } \\
\text { Openaccess }\end{array}$} \\
\hline & & & \\
\hline & $\begin{array}{l}\text { DOI: } 10.1159 / 000445737 \\
\text { Publisnea onine:-1Viay 19, } 2016\end{array}$ & $\begin{array}{l}\text { (c) } 2016 \text { The Author(s) } \\
\text { Published by S. Karger AG, Basel } \\
\text { www.karger.com/crg }\end{array}$ & \\
\hline & $\begin{array}{l}\text { This article is licensed under } \\
\text { International License (CC BY-N } \\
\text { Usage and distribution for comm }\end{array}$ & $\begin{array}{l}\text { mons Attribution-NonCommercial } 4.0 \\
\text { rger.com/Services/OpenAccessLicense). } \\
\text { quires written permission. }\end{array}$ & \\
\hline
\end{tabular}

\title{
Jaw Dislocation as an Unusual Complication of Upper Endoscopy
}

\author{
Evan S. Dellon David Steele \\ Center for Esophageal Disease and Swallowing, Division of Gastroenterology and \\ Hepatology, University of North Carolina School of Medicine, Chapel Hill, N.C., USA
}

\section{Keywords}

Temporomandibular joint dislocation · Upper endoscopy · Complications

\begin{abstract}
This case report presents an unusual complication of upper endoscopy, resulting in jaw dislocation. Temporomandibular joint dislocation is commonly reported in association with anesthesia and intubation, but it is not widely recognized as a complication of gastrointestinal endoscopy. This report also reviews the current literature regarding this complication and discusses the potential causes of dislocation, differential diagnoses for jaw pain following endoscopy, and recommendations for prevention.

(C) 2016 The Author(s)

Published by S. Karger AG, Basel
\end{abstract}

\section{Introduction}

Jaw dislocation has been reported in the literature as a rare complication of bronchoscopy, intubation, transesophageal echocardiogram, and otolaryngology and dentistry procedures [1-4]. However, temporomandibular joint (TMJ) dislocation is not commonly recognized by gastroenterologists as a potential complication of esophagogastroduodenoscopy (EGD) [5-10]. In this report, we present a patient with temporomandibular displacement after EGD and discuss how to identify this complication, the differential diagnosis of postendoscopy jaw pain, and the methods for prevention. We will also review the literature regard- 


\section{Case Reports in Gastroenterology}

Case Rep Gastroenterol 2016;10:146-150

(c) 2016 The Author(s). Published by S. Karger AG, Basel www.karger.com/crg

Dellon and Steele: Jaw Dislocation as an Unusual Complication of Upper Endoscopy

ing other cases involving temporomandibular displacement following upper endoscopy to assist in the future identification of this complication.

\section{Case}

A 48-year-old woman with hypertension, rheumatoid arthritis, seasonal allergies, and long-standing solid food dysphagia presented to our gastroenterology clinic with progressively worsening dysphagia and transient food impaction. The patient reported approximately 7 years of solid food dysphagia, but prior to this, has had no upper gastrointestinal symptoms, trouble swallowing, or dietary modification. She had sought prior gastrointestinal evaluation, and an endoscopy 2 years after symptom onset showed rings and furrows, but biopsies were not obtained and dilation was not performed. Though no specific treatments were initiated, the patient did note an improvement in her ability to swallow following the procedure.

One year prior to her presentation, she developed recurrent solid dysphagia which progressively worsened. Solid foods, particularly bread and meat, would get stuck in the upper chest and resulted in transient impactions 2-3 times per week. In most instances, if she waited, the food would ultimately pass; however, in some cases, she would have to regurgitate the food. She reported eating slowly, taking small bites, chewing thoroughly, and drinking a lot of liquids during meals. Because of suspicion of eosinophilic esophagitis (EoE), she was placed on a proton pump inhibitor (omeprazole $20 \mathrm{mg}$ twice daily), and repeat endoscopy was performed. She was given propofol for sedation, and the endoscopy went smoothly, but it was noted that she was yawning multiple times during the procedure.

Immediately after the procedure, the patient experienced severe left-sided facial pain. On examination, there was a spasm over the left masseter muscle, and she was unable to close her mouth. In an attempt to control her pain and relax her muscle spasm, the patient was given $25 \mu \mathrm{g}$ of fentanyl and a 30 -mg dose of propofol, but these were not successful. Given the severity of her pain and her inability to close her mouth, she was referred to the emergency department for suspicion of jaw dislocation.

In the emergency department, the patient required additional doses of fentanyl for pain control. A maxillofacial CT showed an anterior dislocation of the left TMJ without a mandibular fracture (fig. 1, 2). The initial attempt at jaw reduction using a 2-mg intravenous dose of midazolam sedation was unsuccessful. The oral maxillofacial surgery team was consulted and successfully reduced the jaw dislocation following administration of a 100-mg dose of ketamine. She received a jaw strap and was discharged home. She remained in the jaw strap and on a mechanical soft diet for 7 days. She was closely followed over the next several days and rapidly improved to her baseline. Further history was obtained and while she has had no prior jaw dislocation, she did report intermittent jaw pain. Of note, the results of the biopsy from her endoscopy confirmed the diagnosis of EoE, which will require the patient to undergo future endoscopies.

\section{Discussion}

Anterior dislocation of the TMJ is the most common type of jaw dislocation with multiple potential etiologies. Superior and posterior dislocations are rare and almost exclusively associated with trauma and fracture. While anterior dislocation may occur as a result of a 
dystonic reaction to drugs and seizures, a majority of anterior dislocations occur with extreme opening of the mouth [11]. These causes may include eating, singing, laughing, vomiting, or even yawning [11], as was noted for the patient presented here. In a retrospective study of 96 cases of TMJ dislocation, extreme mouth opening while yawning was identified as the most common cause of dislocation, representing approximately $46 \%$ of reported cases [12]. The other common etiology of this type of dislocation is iatrogenic. Several reports discuss TMJ dislocation as a complication of bronchoscopies, dental procedures, induction of anesthesia, and transesophageal echocardiograms [1-4]. Amongst the potential iatrogenic causes, several additional factors have been identified as potential sources for increasing the risk of jaw dislocation in cases outside of gastroenterology. These include prolonged procedure time [1], increased age [2], and relaxation of the musculature caused by sedating medications [3].

We present a case of jaw dislocation as a consequence of upper endoscopy. This is an unusual complication of EGD, and we have only been able to identify 6 cases reported within the last 30 years in patients ranging from 23 to 83 years of age [5-10]. In these cases, the endoscopies were uncomplicated, but immediately following each procedure, the patients complained of facial pain and the inability to close their mouth (similar to our case), with two exceptions. The first was a patient who was intubated prior to the procedure and unable to communicate symptoms [6]; the second was a patient who presented the following day with facial pain and the inability to close her mouth appropriately [9]. Another consistent finding amongst these cases and our patient is that all had anterior dislocations [9]. However, the ability to reduce these displacements varied based on the degree or laterality of dislocation and patient experience with prior displacements. For example, in the report from Lacy et al. [5], a patient who had no prior history of dislocations experienced a bilateral displacement which required additional sedation for successful reduction. However, in a report of a young woman with only a unilateral displacement and a well-documented history of TMJ dislocations, the patient was able to reduce the displacement herself with the assistance of her endoscopist requiring no further sedation [10]. While a prior history of dislocation is a risk factor for jaw displacement following EGD [10], the lack of a predisposing history does not exclude patients from the possibility of having a TMJ dislocation. Of the 6 reported cases, only 2 patients reported a prior history of TMJ displacement $[6,10]$. Anesthesia is frequently cited as a risk factor for TMJ dislocation because it relaxes the masseter and temporalis muscles, which usually act as stabilizers. While propofol was used in our case, in the other reports of jaw dislocation following EGD, a benzodiazepine, midazolam or diazepam, was used for sedation [5-10]. While most reported cases of TMJ displacement from a gastroenterology procedure occur as a complication of EGD, 2 cases of jaw dislocation have been reported following endoscopic retrograde cholangiopancreatography, and 1 was noted after percutaneous endoscopic gastrostomy tube placement [13-15].

While jaw dislocation was felt to be the most likely source of this patient's jaw pain following endoscopy, reduction was not immediately attempted due to concern for other possible causes. When patients suffer from TMJ dislocation, they will often be unable to close their mouth and have drooling and garbled speech along with pain [11]. For this reason, acute stroke was part of the differential diagnosis and should always be considered in the correct clinical context. Another factor considered in this case was a pathologic fracture. While the diagnosis of TMJ dislocation is made based upon clinical examination, radiographic imaging should always be performed to exclude any type of mandibular fracture. The disadvantage of delayed reduction is an increased risk of developing muscular spasms, which ultimately makes reducing the dislocation more challenging [8]. 
Preventing recurrent jaw dislocations is a pertinent issue for our patient. She will require additional upper endoscopies for surveillance of treatment response given her new diagnosis of EoE. However, no specific recommendations exist at this time regarding measures that can prevent jaw dislocation during an endoscopy. Given that most jaw dislocations seem to occur as a result of anesthesia, appropriate surveillance of patients who may be over- or undersedated can be important in preventing complications from endoscopy. While it is important to note if a patient has a prior history of TMJ dislocation, the lack of such a history should not diminish monitoring for displacement after the procedure. While jaw dislocation is a very rare complication of upper endoscopy, it is important for gastroenterologists to be aware of this possibility, recognize it in the recovery area, and appreciate the differential diagnosis. Similar to previous recommendations $[9,10]$, as a part of routine evaluation, it may be beneficial to observe patients during mastication after the procedure.

\section{Statement of Ethics}

The authors have no ethical conflicts to disclose. Informed consent was obtained from the presented patient.

\section{Disclosure Statement}

The authors have no conflicts of interest.

\section{References}

1 Kim SK, Kim K: Subluxation of the temporomandibular joint. Unusual complications of transoral bronchoscopy. Chest 1983;83:288-289.

2 Kepron W: Bilateral dislocations of the temporomandibular joint complicating fiberoptic bronchoscopy. Chest 1986;90:465.

-3 Anantharam B, Chahal N, Stephens N, Senior R: Temporomandibular joint dislocation: an unusual complication of transoesophageal echocardiography. Eur J Echocardiogr 2010;11:190-191.

-4 Gambling DR, Ross PL: Temporomandibular joint subluxation on induction of anesthesia. Anesth Analg 1988;67:91-92.

-5 Lacy PD, Lee JM, O'Morain CA: Temporomandibular joint dislocation: an unusual complication of upper gastrointestinal endoscopy. Am J Gastroenterol 2000;95:3653-3654.

-6 Lorenzo D, Boissier F, Prost A, Gallois C, Faisy C: Bilateral temporomandibular joint dislocation after upper gastrointestinal endoscopy in an intensive care unit patient: a rare complication. Endoscopy 2014;46(suppl 1):E538.

7 Nijhawan S, Nepalia S: Dislocation of temporomandibular joint after upper gastrointestinal endoscopy. Trop Gastroenterol 1994;15:232.

8 Solakoglu AG, et al: Temporomandibular joint dislocation after gastroendoscopy: a case report. Br J Med Med Res 2013;3:503-507.

-9 Mangi Q, Ridgway PF, Ibrahim Z, Evoy D: Dislocation of the mandible. Surg Endosc 2004;18:554-556. Savas MC, Gulsen MT, Kadayifci A: Habitual dislocation of the temporomandibular joint during upper endoscopy. Gastrointest Endosc 2004;60:325.

11 Mendez DR: Reduction of temporomandibular joint (TMJ) dislocation; in Stack AM (ed): UpToDate. Waltham, MA (Accessed on October 31, 2015).

12 Ugboko VI, Oginni FO, Ajike SO, Olasoji HO, Adebayo ET: A survey of temporomandibular joint dislocation: aetiology, demographics, risk factors and management in 96 Nigerian cases. Int J Oral Maxillofac Surg 2005;34:499-502.

13 Fayman MS, Dunn SE, Wellsted M: Two unusual complications related to fibre-optic endoscopy. S Afr Med J 1984;65:354. 


\section{Case Reports in Gastroenterology

\begin{tabular}{l|l}
\hline Case Rep Gastroenterol 2016;10:146-150 \\
\hline $10.1159 / 000445737$ & $\begin{array}{l}\text { C 2016 The Author(s). Published by S. Karger AG, Basel } \\
\text { www.karger.com/crg }\end{array}$ \\
\hline
\end{tabular} \\ Dellon and Steele: Jaw Dislocation as an Unusual Complication of Upper Endoscopy}

\footnotetext{
14 To EW, Pang PC, Lee DW: Temporomandibular joint dislocation during endoscopic retrograde cholangiopancreatography examination. Endoscopy 2000;32:S36.

15 Rosemore J, Nikoomanesh P, Lacy BE: Bilateral temporomandibular joint dislocation after PEG tube placement. Gastrointest Endosc 2004;59:146-147.
}

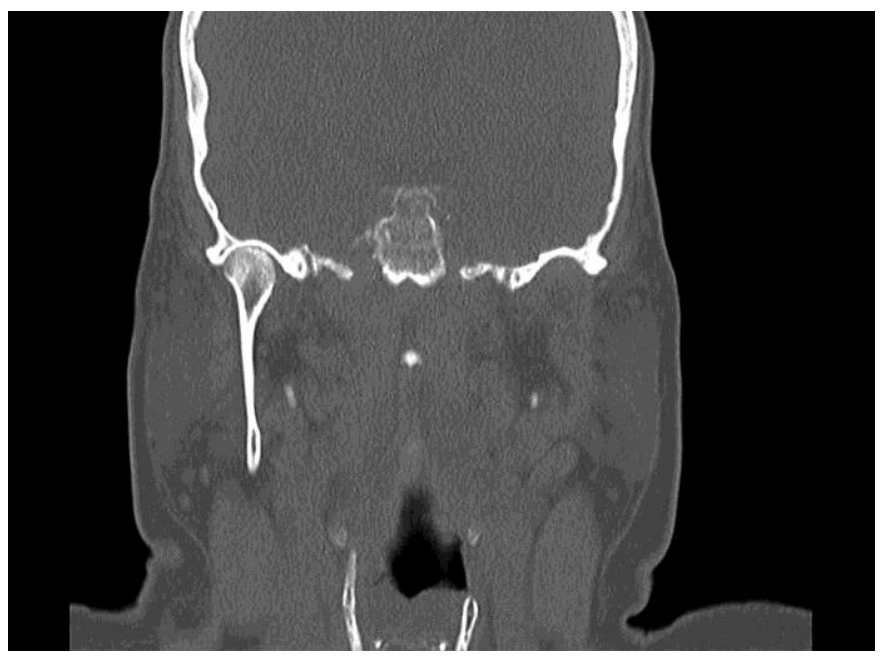

Fig. 1. Coronal view of a head CT showing a complete left TMJ dislocation with anterior displacement of the mandibular condyle. In this image, while the right TMJ is noted, the left TMJ is not seen.



Fig. 2. Axial view of the same head CT showing complete left TMJ dislocation with anterior displacement of the mandibular condyle. The arrow indicates the dislocation. 